\title{
Bergson, truth-making, and the retrograde movement of the true
}

\author{
Daniel Schulthess, Université de Neuchâtel
}

\begin{abstract}
Henri Bergson (1859-1941) was one of the main exponents of evolutionary thinking in the later nineteenth and early twentieth century. He gave that kind of thinking an unprecedented metaphysical turn. In consequence of his versatility he also encountered the notion of truth-making, which he connected with his ever-present concerns about time and duration. Eager to stress the dimension of radical change and of novelty in the nature of things, he rejected (in one form) what he called "the retrograde movement of the true" while championing it - with undeniable delight in the air of paradox - in a derivative form. In the paper I explain what "the retrograde movement of the true" consists in - in its two forms.
\end{abstract}

\section{Introduction}

We may have different levels of expectation relative to an account of truth-making. Many things may vary: the questions to be addressed, the distinctions to be made, the logical aspects to be taken care of, and the kind of dialectic to be engaged in. A minimal notion of what an account of truth-making should consist of may include the following elements:

-the explicit identification of truth-bearers;

-the correlative identification of "that in virtue of which" a given true truth-bearer is true; i.e., of the relevant truth-makers;

-the idea of a specific, asymmetric, non causal relation, between a truth-maker and the correlative true truth-bearer: with the phrase "that in virtue of which", this idea is already implicit in the preceding clause.

Furthermore, an account of truth-making may either have the aim of articulating a formal theory of truth - the theory being an end it itself -; or it may do some work in addressing other issues. A comparison can be made with ethics, where we find, as distinctive areas of inquiry, ethical theory on the one hand, and applied ethics on the other.

In an author like Henri Bergson, we discover an account of truth-making to the extent that our requirements remain minimal, technically speaking; and that we accept that 
the account stays embedded in the treatment of questions which go beyond the formal theory of truth.

This is not to say that we should forget about an account such as Bergson's; and this for two main reasons: (i) On the side of the theory of truth-making, we may benefit from extending its thematic spectrum to such an author, even quite radical, because of the wealth of interesting investigations which his writings contain. Bergson's case study in truth-making will provide an original material, able to enrich other, more focused accounts. (ii) If we take the side of the understanding of Bergson, it is obvious that we have to articulate certain of his preoccupations in terms of an account of truth-making. They cry out for such a treatment. As we shall see, Bergson does not belong properly, given his views on truth-making, to the context of pragmatism, to which no doubt he was close in some respects ${ }^{1}$. What he has to say about truth requires the rejection of the anti-realism otherwise characteristic of pragmatism. One last introductory consideration: Bergson, given his philosophical predilections, addresses most issues from a concern for the role of time and duration. This is true also with the present topic. At an earlier stage, accounts of truth-making did little to interfere with views on the metaphysics of time; but this has changed significantly. Following Armstrong's chapter on time in his 2004 (ch. 11), we have seen a growing interference between accounts of truth-making and the metaphysics of time. So the obstacles to the idea of addressing the views of Bergson concerning truth-making can be overcome ${ }^{2}$.

\section{A minimal account}

What Bergson has to say, as far as his account of truthmaking is concerned, belongs principally to the first and third chapters of his collection of articles of $1934^{3}$, respectively: "The Retrograde Movement of the True" ("Le mouvement rétrograde du vrai") and "The Possible and the Actual" ("Le possible et le réel"). The title "The Retrograde Movement of the True" is slightly odd, because this retrograde movement is something which Bergson precisely rejects in its primitive form (though he accepts it in a derivative form). We may say that according to him there is a problem of the

\footnotetext{
${ }^{1}$ See ch. 7, “On William James' Pragmatism: Truth and Reality” in his 1959a.

${ }^{2}$ My interest in the topic of this paper originated with a mention of Bergson's view on "retrogradation of truth" by Vuillemin 1996, pp. 148-149.

${ }^{3}$ Ironically enough, the main treatment of these questions was elaborated by Bergson for his English lectures at Columbia University (New York) in 1913. See Bergson 1959a, p. 1264, fn. 1. The lectures have not been recovered to this day.
} 
retrograde movement of the true, and that his analysis of this problem leads him to the conclusion that in primitive form there is no such thing as the retrograde movement of the true.

Now the problem is couched in terms that depend on an account of truthmaking minimal as it may well be. So let me first say a few words about the three basic issues listed at the beginning of this paper.

\section{-Truth-bearers}

Bergson's truth-bearers are basically judgements, dated acts of judgement; they have an inner structure, given that they contain terms. Otherwise, Bergson gives no specific account of judgement-content. He moves without much ado from the act of judging as a token, to the judgement as a type; and from there to the judgement as an ideal content (1959a, p. 1263).

\section{-Truth-makers}

Bergson's account here is not fine-grained either: the truth-maker is "the occurrence (apparition) of a thing or of an event", which the judgement "records" (1959a, p. 1263).

-The relation

Bergson writes very little about this relation: "the judgement, which records the occurrence of a thing or of an event, can come only after them" (1959a, p. 1263). The phrase "can only come after them" jointly conveys the temporal aspect of succession and the ontological aspect of asymmetric dependence.

\section{The canonical view of judgement}

Bergson basically addresses only one type of judgment: singular, historical, contingent judgement. And, we may add, affirmative judgement. Once an event has taken place, its occurrence can then be stated, it can be recorded by the judgment. Thus the formation of a given truth-bearer is posterior to the relevant truth-maker. For Bergson, the lesson is this: there is basically an insertion in time for any historical judgement: "[the judgment] thus has its date" (1959a, p. 1263). When he writes this, he speaks of the date of the judgment - as an act. This date indicates the time of the very existence of the true judgement. It does not overlap with the date of the event 
(which features in the judgement-content, locating the event in time). Indeed, what is at stake is not the time of the truth of a truth-bearer either (in the sense in which a tensed judgement may first be false and then become true at a time). Here the truthbearer is not exposed to truth-value changes, because the content includes a date. So overall in a correct account of truth-bearers we must take heed of two dates: the usual date which indicates the temporal location of the event, and another date which determines the time at which the judgement is formed. This time is dependent on the date of the relevant event, and is slightly posterior to it. This has the following structure (Diagram 1):

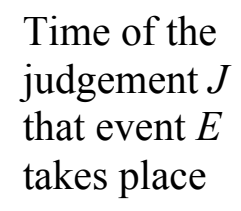

\section{Diagram 1}
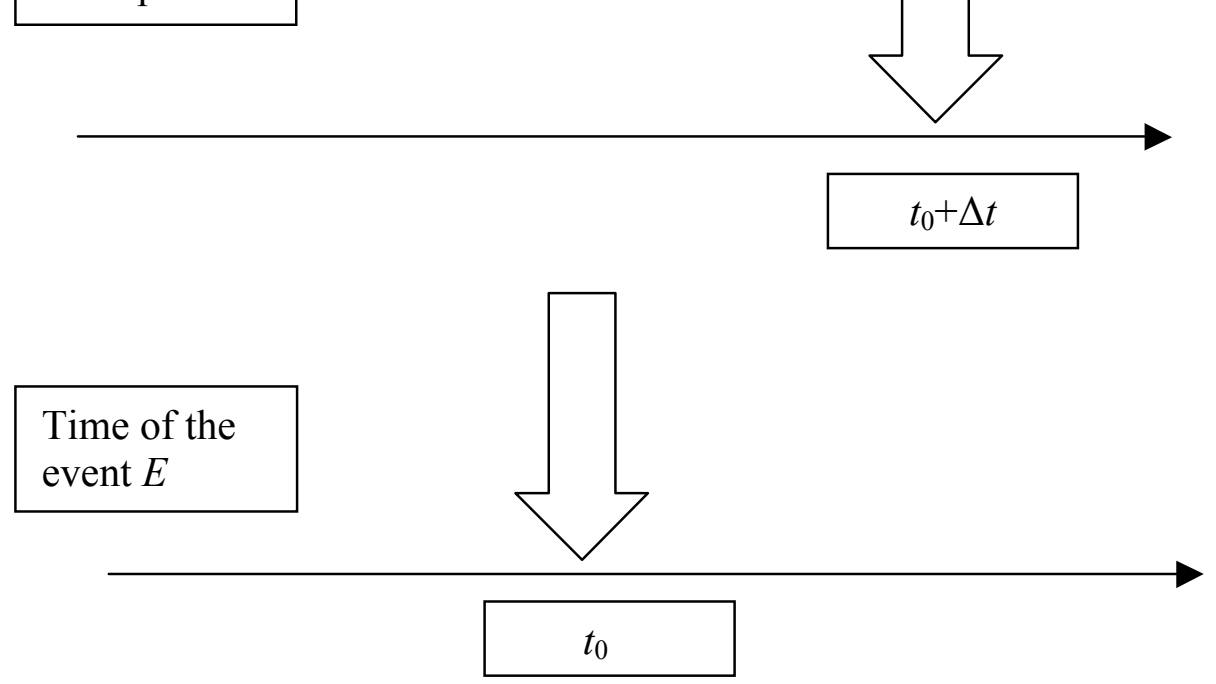

We may conclude that according to Bergson, a judgement in canonical form (CF) has to be given in the following way:

(CF) At $t_{0}+\Delta t$ there is the true judgement $J$ that the event $E$ takes place at $t_{0}$

This is the legitimate structure concerning judgement; it applies as such to historical judgements. Now we wish to express the dependence of such a formula (CF) on the realization of the event (DE for "dependence"): 
(DE) If at $t_{0}+\Delta t$ there is the true judgement $J$ that the event $E$ takes place at $t_{0}$, then $E$ takes place at $t_{0}$

An additional condition must be provisionally taken into account; namely, that the event has been observed (DEO for "dependence" and "observation"). (We come back to this later.)

(DEO) if at $t_{0}+\Delta t$ there is the true judgement $J$ that the event $E$ takes place at $t_{0}$, then ( $E$ takes place at $t_{0}$, and $E$ gets observed at $t_{0}$ )

All of this is unproblematic, to Bergson, or to anybody else.

\section{The retrograde movement of the true: how it works}

Now I come closer to the properly Bergsonian topic of the retrograde movement of the true. In order for the retrogradation to take place, a first step is needed. The "observation clause" - the requirement for an actual observation to have taken place has to be lifted from (DEO), and replaced with a "de jure conditional" (DJ, for de jure, en droit). Bergson describes this in the following way: "The true judgement may well have been left unformulated: it did set itself de jure, before it was factually set out." (1959a, p. 1263) Presumably the idea is that in itself the actual observation makes no real difference to the proceedings. The suppression of the clause concerning actual observation also allows us to treat the occurrence of the event as sufficient for the correlative "virtual" judgement.

(DJ) If the event $E$ takes place at $t_{0}$, then at $t_{0}+\Delta t$ there is de jure the true judgement $J$ that $E$ takes place at $t_{0}$

As far as I can see, Bergson does not object to this specific step, which leaves the time constraints intact. Given that he does not insist on actual observations, obviously he is no verificationist. The kind of ontology of judgement and terms he stands for, remains in need of a thorough investigation.

Now comes the decisive step. The view prevails in common thinking that the first date featuring in the canonical form (CF) can be suppressed. Bergson writes: "To 
every true [judgement] [...] we impress a retrograde movement." (1959a, p. 1263) Elsewhere he comments: "[Modern philosophers] make of truth something which is anterior to the well-determined act of formulating it for the first time." (1959a, p. 1446; see also p. 1445)

On account of this step, we switch, from a dated view given by (CF) above, to an omnitemporal view of judgement (OV for "omnitemporal view).

$(\mathrm{OV})$ If at time $t$ there is the true judgement $J$, then at all times there is the true judgement $J$

This principle (OV) comes into application from the use of our understanding (intelligence.) Bergson writes: "This date [which attaches the existence of the truthbearer to a particular time] gets immediately erased, in virtue of the principle, which is rooted in our understanding, that every truth is eternal." (1959a, p. 1263) In Bergson, human understanding has to do with action: "understanding is well fitted to deal with material things" (1959a, p. 1279). He never tires of insisting on the adaptation of understanding to practical concerns.

Taking advantage of the principle (OV), we can make the following substitution in the principle (DJ) above, and reach the principle (AT) (AT for "any time"):

(AT) If the event $E$ takes place at $t_{0}$, then at any time there is de jure the true judgement $J$ that $E$ takes place at $t_{0}$

Of course there is no problem if the judgement $J$ is moved to the right, down the arrow of time. But if we move the judgement $J$ to the left, up the arrow of time, problems are in view. Here we reach the "retrograde movement of the true" (RMT), represented in Diagram 2. 


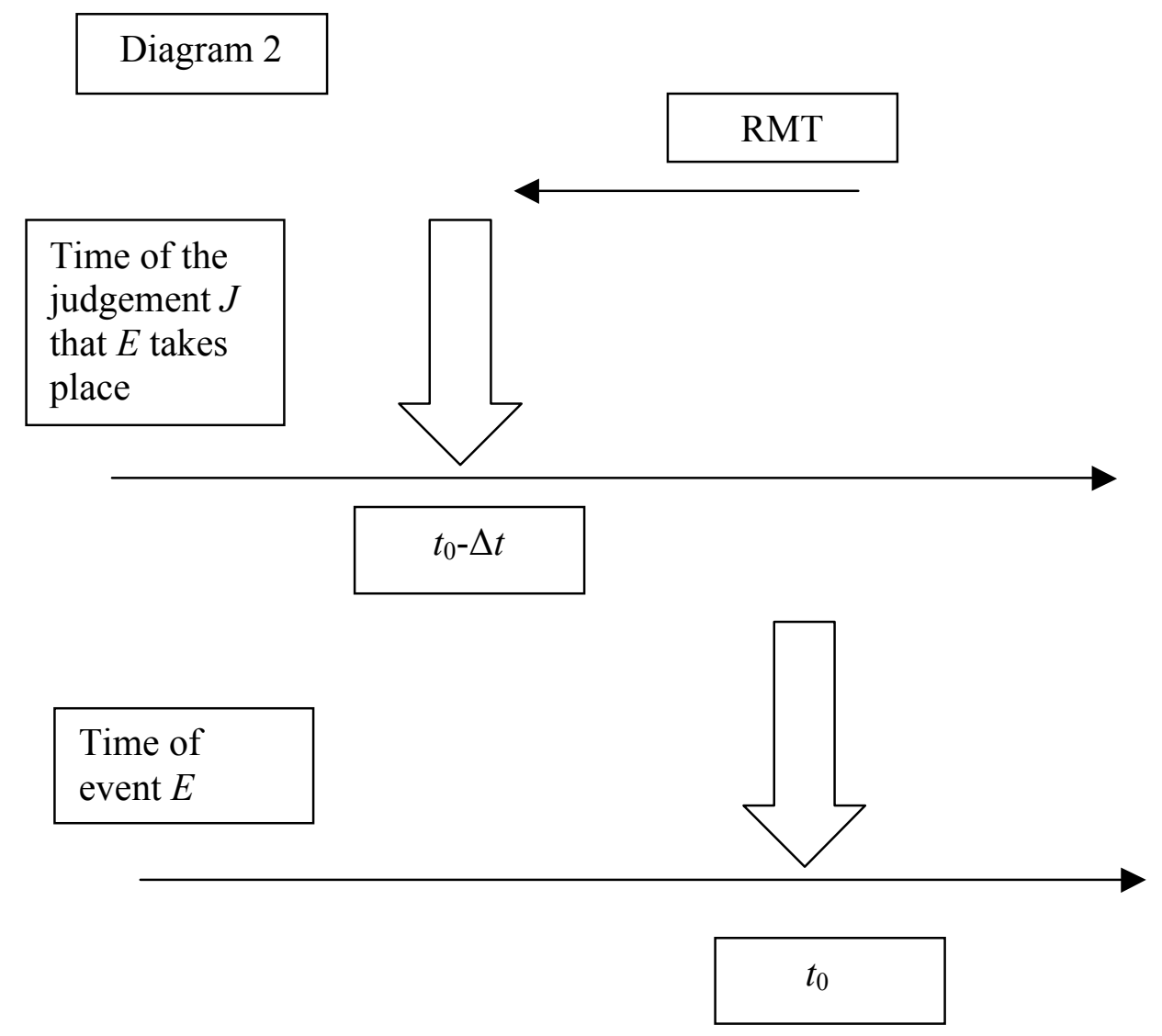

In order for the problem to arise in its primitive Bergsonian form, we have yet to introduce a tensed view of time and then to pull $t_{0}$ into the future. This means that we have to insert, in Diagram 2, an index $N$ (N for "now") between $t_{0}-\Delta t$ and $t_{0}$; which brings us to the following formulation $\left(\mathrm{RMT}_{\mathrm{FT}}\right)(\mathrm{FT}$ for "future time"):

$\left(\mathrm{RMT}_{\mathrm{FT}}\right)$ If $E$ takes place at a future time $t_{0}$, then at any time (including at future times $<t_{0}$, at present and in the past) there is de jure the true judgement $J$ that $E$ takes place at that future time $t_{0}$

Strikingly, as we shall see, (RMT) will also come in an innocuous form, $\left(\mathrm{RMT}_{\mathrm{PT}}\right)(\mathrm{PT}$ for "past time"). This means that we have to insert, in Diagram 2, an index $N(\mathrm{~N}$ for "now") to the right of $t_{0}$.

(RMT $\mathrm{RT}_{\mathrm{PT}}$ ) If the event $E$ takes place at a past time $t_{0}$, then at any time (including at times past $<t_{0}$ ) there is de jure the true judgement $J$ that $E$ takes place at that past time $t_{0}$. 


\section{On the convertibility of prior truth and anterior possibility}

Before going into more detail, we must notice that the retrograde movement of the true closely connects with the notion of the possible such as it is treated by Bergson (see 1959a, ch. 3). We may say that the retrograde movement of the true and a corresponding "retrograde movement of the possible" fully overlap. To say: there is an antecedently true judgement about an event $E$, on Bergson's account, amounts to saying: it is antecedently possible that $E$; and vice-versa. This is surprising, because on the usual view there are unrealized possibilities. In such cases we would like to say that it is antecedently possible that an event $E$ will happen; but not, at the same time that there is the antecedently true judgement that $E$ will happen (because $E$ will not happen). Bergson rejects this. Generally speaking, Bergson is strongly opinionated on the issue of possibility ${ }^{4}$, and his position can be expressed by means of what is usually called the "principle of plenitude" (PP). The principle (PP) says that what is possible also gets realized at some time.

(PP) If the event $E$ is possible (untensed), then at some time $E$ is actual (untensed)

In Bergson's view a principle of plenitude applies in a degenerate way, which specifies an even tighter link between possibility and actuality:

$\left(\mathrm{PP}_{\mathrm{B}}\right)$ If the event $E$ is possible $\mathrm{E}$ (tensed), then $E$ is actual (tensed)

Here is how Bergson expresses himself: "There is more, and not less, in the possibility of each of the successive states, than in their actuality. Indeed, the possible is nothing but the actual, with a mental act added to it; a mental act which projects the image of the actual in the past once the actual has taken place.” (1959a, p. 1339) Or alternatively: "the creation of possibilities coincides with the creation of the corresponding actualities; they are not created ahead of their actualities." (1959a, p. 1262) Given these elements, the basic insight comes as the contraposition of $\left(\mathrm{PP}_{\mathrm{B}}\right)$ :

(Contrap $\mathrm{PPB}$ ) if the event $E$ is not actual (tensed), then $E$ is not possible (tensed)

\footnotetext{
${ }^{4}$ Quite in tune with other philosophers of the early twentieth century - one thinks of R. Carnap's Scheinprobleme (1928) -, Bergson holds that many questions taken to be important in philosophy are merely consequences of defective assumptions. The usual view of possibility involves such assumptions.
} 
This formula captures the restrictive view of possibility characteristic of Bergson (see 1959a, p. 1267). In what follows, then, "antecedently true" and "antecedently possible" will be treated as convertible. Bergson expresses much of what he wants to say in relation to the possibility of an event $E$, rather than in relation with the true judgement that an event $E$ is to take place.

\section{The retrograde movement of the true: what is not wrong with it}

Bergson considers the retrograde movement of the true $\left(\mathrm{RMT}_{\mathrm{FT}}\right)$ as illegitimate. What is at stake for him, we may say, is the existence of certain temporal limits of truth-making, limits that $\left(\mathrm{RMT}_{\mathrm{FT}}\right)$ fails to respect (though $\left(\mathrm{RMT}_{\mathrm{PT}}\right)$ does not!). But why should we admit such limits? What's wrong with $\left(\mathrm{RMT}_{\mathrm{FT}}\right)$ ? Is this structure not basic for all our deliberation, for all our previsions, and therefore for our capacity to be active on the basis of anticipation? In anticipation, we judge now that such and such an event will happen, and often we are right. After deliberation, we end up doing - quite often - one of the things we have been deliberating about. The conjunction of our anticipation of an event $E$ and of the future realization of $E$ then satisfies the formula $\left(\mathrm{RMT}_{\mathrm{FT}}\right)$ without problem - or so it seems, when we look at this retrospectively.

I begin this section by considering two points that do not count for the explanation of the illegitimacy of $\left(\mathrm{RMT}_{\mathrm{FT}}\right)$.

-Bergson's criticism does not relate to the epistemic difficulties of prevision. His problem is not one which would have the following expression: judgements as such aptly characterize what will happen, but given that we cannot know about these future events, we better avoid making any judgements about them. This is not what Bergson argues about ${ }^{5}$. His quarrel with $\left(\mathrm{RMT}_{\mathrm{FT}}\right)$ is really linked to the question of truth. -Bergson's criticism does not overlap with the long-established problems of "future contingents" and of "logical determinism". In spite of his familiarity with Aristotelian topics, his concern is not specifically with what happens with future events normally given as contingent. And however close he may be to the great Aristotelian tradition according to which truth about the future is a threat for matters that are taken as

\footnotetext{
${ }^{5}$ Of course epistemic restrictions to foreknowledge can be philosophically sophisticated as Karl Popper's example shows (1960).
} 
important, he has a view of this threat that is different from the one which constitutes the usual problem of future contingents. He never identifies as a problem that perhaps - true judgements about the future will make the future necessary, suppress contingency, etc. Bergson's criticism of $\left(\mathrm{RMT}_{\mathrm{FT}}\right)$ is focused on a much more specific view he holds about the relation between the truth-bearer and the truth-maker. And given his stance on this, the problem of future contingents vanishes. To bring the point to a pitch: given that $\left(\mathrm{RMT}_{\mathrm{FT}}\right)$ is false (in this case there is no retrograde movement of the true), the traditional problem of future contingents does not arise at all!

\section{The temporal condition on the representative capacities of the judgement}

Let us come back to our question: Bergson considers the retrograde movement of the true $\left(\mathrm{RMT}_{\mathrm{FT}}\right)$ as illegitimate. What is at stake for him, we may say, is the existence of certain temporal limits of truth-making, limits that $\left(\mathrm{RMT}_{\mathrm{FT}}\right)$ fails to respect. But why should we admit such limits? What's wrong with $\left(\mathrm{RMT}_{\mathrm{FT}}\right)$ ?

The point is that we have to take heed, we may say, of a "time of the representative capacities of a judgement". This has to do with the content of the judgement, and therefore with its semantics. The semantic condition, requiring a temporal relation between what represents and what is represented, is conveyed by means of the terms that are constitutive of the judgement. Bergson puts his point in the following rhetorical interjections: "As if a judgement could have pre-existed to the terms which enter into its composition! As if these terms would not themselves date from the time when the objects which they represent did appear!" (1959a, p. 1263) Basically the representative capacity of a judgement concerning an event $E$ cannot be formed ahead of $E$. Alternatively, an event of the same type must be available to account for the representative capacities of the judgement. With this possibility in view, I represent, in Diagram 3, the circumstances in which (RMT) - given the semantic condition can be legitimate. 


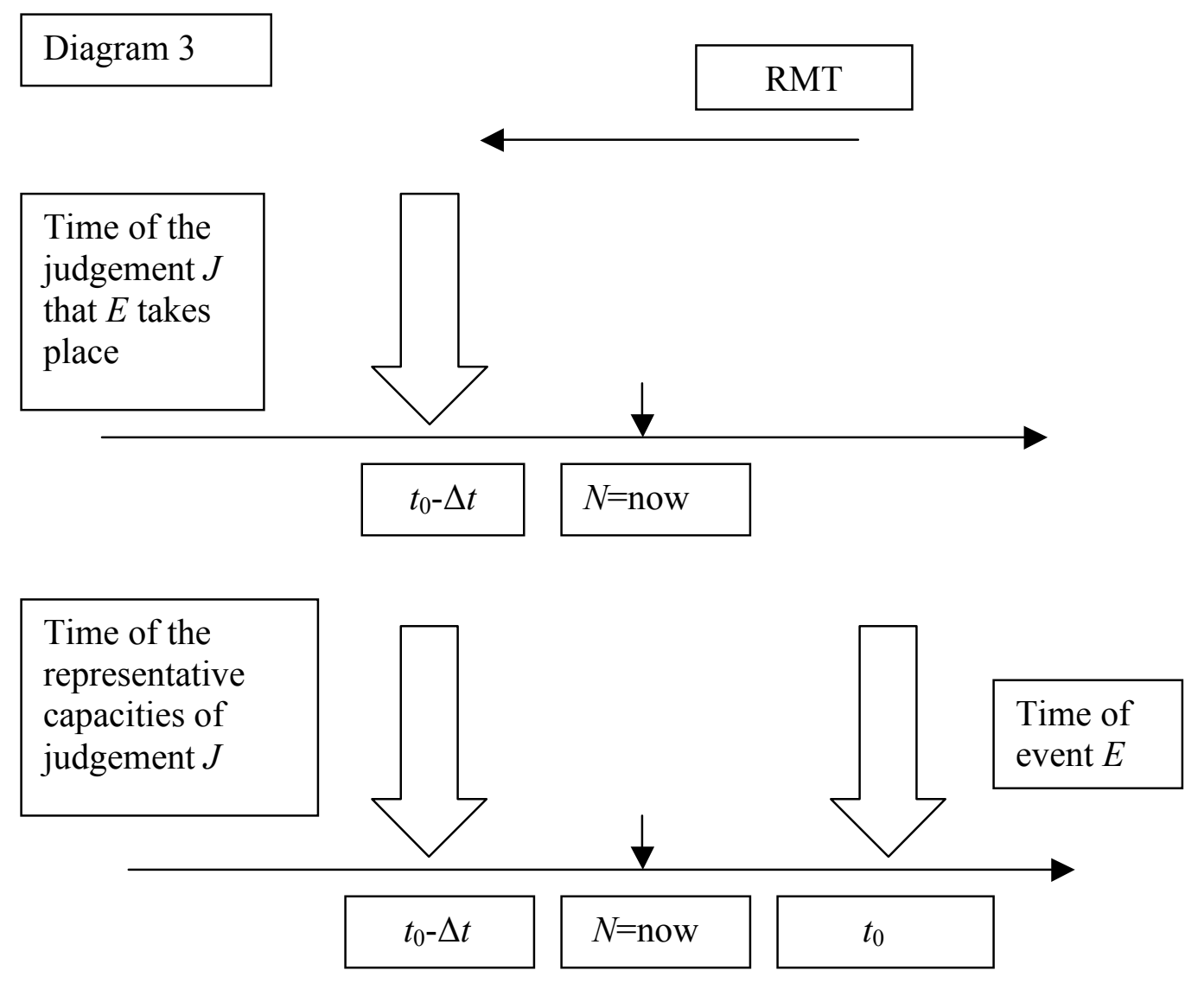

Diagram 3 applies insofar as the non living domain is concerned (here there is a simple unfolding of events, déroulement). Here successive events of the same type or events resulting from a mere rearrangement of data are available. But Diagram 3 does not apply where life or art are concerned. Even though, Bergson avers, "[philosophers] prove unable, whatever they do, to figure out to themselves what radical novelty (nouveauté) and imprevisibility are." (1959a, p. 1260) With radical novelty, the semantic condition of the capacities of the judgment to represent what it has to represent is not satisfied. Then, providing representative capacities for a judgement requires simultaneity in time with the truth of the judgement. In the absence of representative capacities, there is no proper judgement, no truth-bearer. So in such circumstances (RMT) is false.

\section{The retrograde movement of the true: the last twist}

Now that we have reached this point, it is necessary to take account of one more original feature of Bergson's position. The rejection of (RMT) is strictly tied to a tensed view, with consideration of the present/future break. Once we swing over to the past, (RMT) is not restricted any more (see Diagram 4): "Its possibility [i.e. the 
possibility of a given event], which does not precede its actuality, will have preceded it once the actuality has appeared" (1959a, p. 1340).

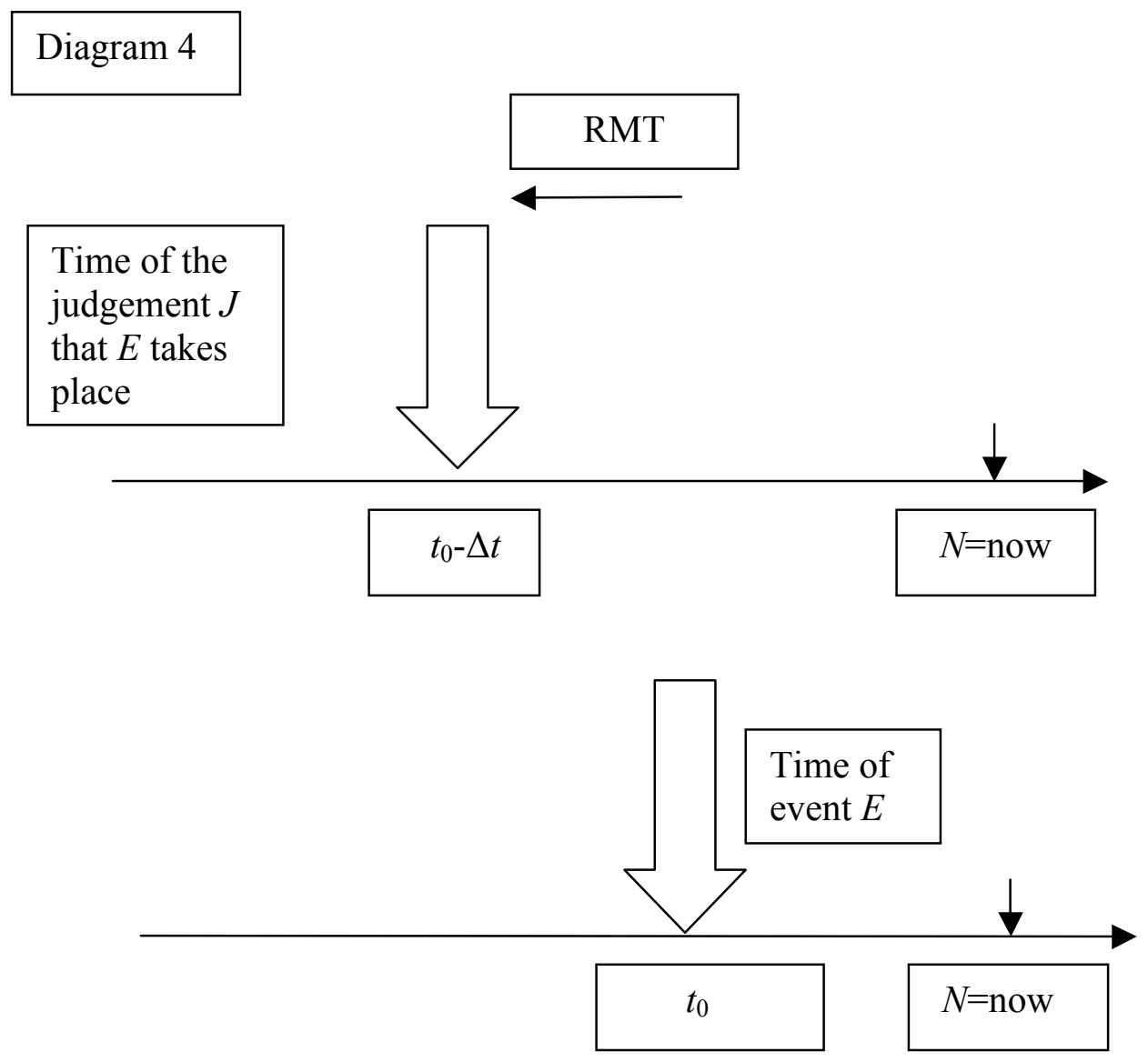

This gives a feeling of a "growing-time" view of time: all the time past is basically available to ensure that for a given judgement, the semantic requirement is met. It is worth remarking also, that in a very specific sense, we have here a breach of the principle of the irrevocability of the past. A given scheme of things, where (RMT) does not apply, passes, with the passage of time, into to a scheme of things where (RMT) does apply. Bergson especially underlines this change in respect to possibility (see 1959a, p. 1340). The retrograde movement of possibility, which does not take place in respect to future events, takes place once those very events are present or past. So the past is changed in respect to the possibilities it contains: past possibilities progressively crop up in virtue of the actualities which in the course of time the novelty of things brings forward.*

*I am very grateful to Colin Geddes (Edinburgh) for his help with the preparation of the English version of this paper. 


\section{References}

Bergson, Henri (1959a/1934), La Pensée et le mouvant, in Bergson 1959b. Translated as The Creative Mind (1946). The translations are mine.

Bergson, Henri (1959b), Euvres, Presses Universitaires de France.

Carnap, Rudolf (2004/1928), Scheinprobleme in der Philosophie, Meiner.

Armstrong, David (2004) Truth and Truthmakers, Cambridge U. P.

Mulligan, Kevin, Simons, Peter, and Smith, Barry (1984), Truthmakers, Philosophy and Phenomenological Research 44/3, p. 287-321.

Popper, Karl (1960), The Poverty of Historicism, Routledge\&Kegan Paul.

Vuillemin, Jules (1996) Necessity or Contingency: The Master Argument, Stanford CSLI Publications. 